\title{
Objects that direct visuospatial attention produce the search advantage for facing dyads
}

\author{
Tim Vestner, Harriet Over, Katie L. H. Gray, and Richard Cook \\ Supplementary material
}

In the main manuscript, we describe ten visual search experiments conducted with human bodies, cameras, cars, chairs, desk fans, guns, desk lamps, bicycles, power drills, and shoes. In each of these experiments, participants also completed the same search task with arrows. The procedure was identical to that described in the main manuscript (example stimuli are shown in Figure S1). In each experiment, half of the participants started with a block of arrows trials (either front-to-front or back-to-back) and half started with a block of object trials (either front-to-front or back-to-back). For the sake of exposition, the results from the ten arrows conditions are presented below as supplementary material. In each experiment, pairs of arrows arranged point-to-point were found faster than pairs arranged base-to-base (all p's < .005), replicating the effect described by Vestner, Gray, \& Cook (2020).
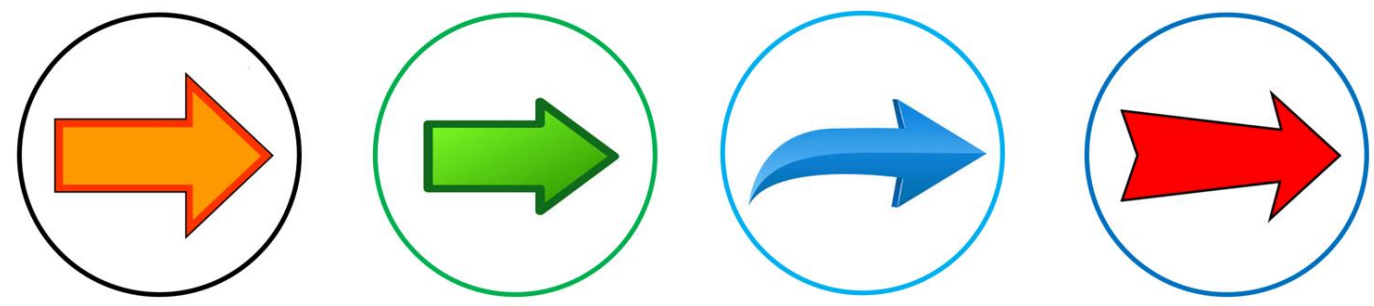

Figure S1. Examples of the arrow stimuli used in the visual search task.

\section{Human bodies}

Results are shown in Figure S2. Those trials where participants responded incorrectly (2\%), or where they took longer than $5 \mathrm{~s}$ to respond $(1.1 \%)$, were excluded from the analysis. The search advantage for facing dyads was seen for arrows. Front-to-front targets $(M=1.76 \mathrm{~s}, S D$ $=0.53 \mathrm{~s})$ were found significantly faster than back-to-back targets $(M=1.94 \mathrm{~s}, S D=0.53 \mathrm{~s})$ $\left[t(39)=6.22, p<.001, d_{z}=0.99, \mathrm{Cl}_{95 \%}=0.12 \mathrm{~s}, 0.24 \mathrm{~s}\right]$. ANOVA with Arrangement (front-tofront, back-to-back) and Stimulus (arrows, human bodies) as within-subjects factors revealed no Arrangement $\times$ Stimulus interaction $\left[F(1,39)=0.11, p=.743, \eta_{p}{ }^{2}=.003\right]$. A significant correlation was seen between participants' search advantage for arrows and bodies $\left[r_{p}=.357\right.$, $p=.024]$.

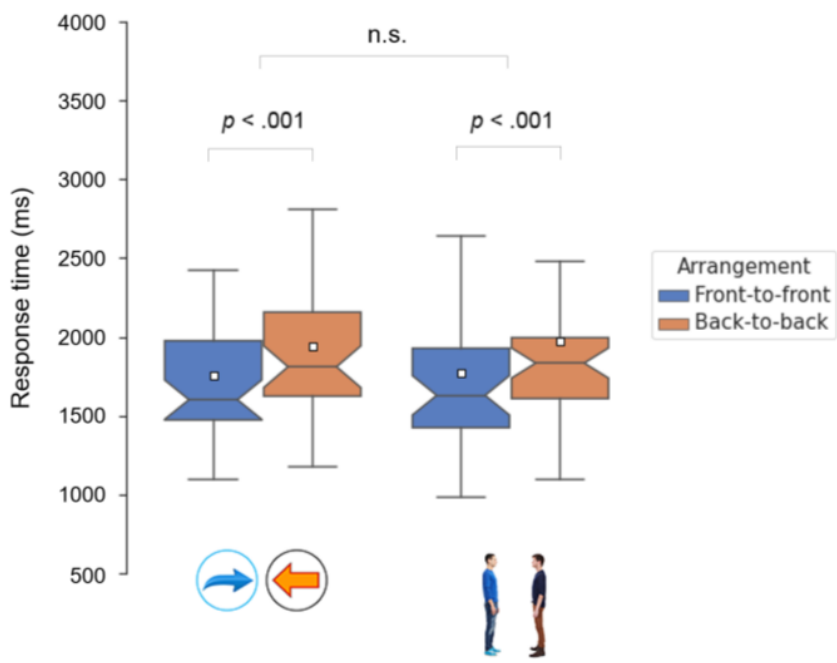

Figure S2. Results from the human bodies experiment. Boxes indicate inter-quartile range. Notches indicate confidence interval of the median. Whiskers indicate $1.5^{*}$ interquartile range. White squares denote the mean. 


\section{Cameras}

Results are shown in Figure S3. Those trials where participants responded incorrectly (1.7\%), or where they took longer than $5 \mathrm{~s}$ to respond $(0.9 \%)$, were excluded from the analysis. The search advantage for facing dyads was seen independently for arrows. Front-to-front targets $(M=1.74 \mathrm{~s}, S D=0.33 \mathrm{~s})$ were found significantly faster than back-to-back targets $(M=1.95$ $\mathrm{s}, S D=0.42 \mathrm{~s})\left[t(39)=5.32, p<.001, d_{z}=0.84, \mathrm{Cl}_{95 \%}=0.13 \mathrm{~s}, 0.29 \mathrm{~s}\right]$. ANOVA with Arrangement (front-to-front, back-to-back) and Stimulus (arrows, cameras) as within-subjects factors revealed no Arrangement $\times$ Stimulus interaction $\left[F(1,39)=0.002, p=.965, \eta_{p}^{2}<\right.$ .001]. A significant correlation was seen between participants' search advantage for arrows and cameras $\left[r_{p}=.451, p=.003\right]$.

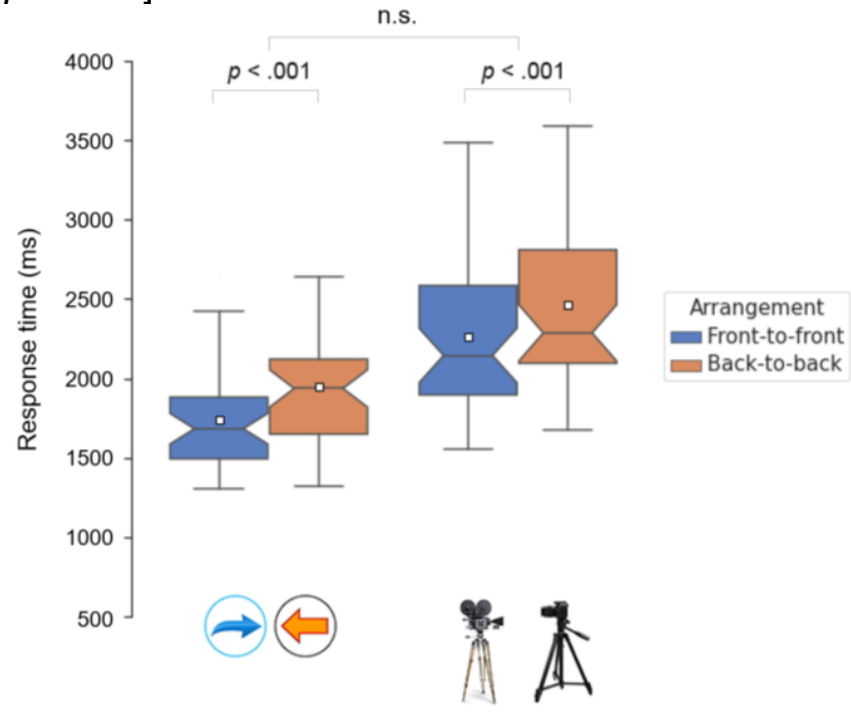

Figure S3. Results from the cameras experiment. Boxes indicate inter-quartile range. Notches indicate confidence interval of the median. Whiskers indicate 1.5 * interquartile range. White squares denote the mean.

Cars

Results are shown in Figure S4. Those trials where participants responded incorrectly (1.9\%), or where they took longer than $5 \mathrm{~s}$ to respond $(1.1 \%)$, were excluded from the analysis. The search advantage for facing dyads was seen independently for arrows. Front-to-front targets $(M=1.69 \mathrm{~s}, S D=0.34 \mathrm{~s})$ were found significantly faster than back-to-back targets $(M=1.88$ $\mathrm{s}, S D=0.44 \mathrm{~s})\left[t(39)=6.52, p<.001, d_{z}=1.03, \mathrm{Cl}_{95 \%}=0.13 \mathrm{~s}, 0.25 \mathrm{~s}\right]$. ANOVA with Arrangement (front-to-front, back-to-back) and Stimulus (arrows, cars) as within-subjects factors revealed no Arrangement $\times$ Stimulus interaction $\left[F(1,39)=3.29, p=.077, \eta_{\mathrm{p}}^{2}=.08\right]$. A significant correlation was seen between participants' search advantage for arrows and cars $\left[r_{p}=.352, p=.026\right]$.

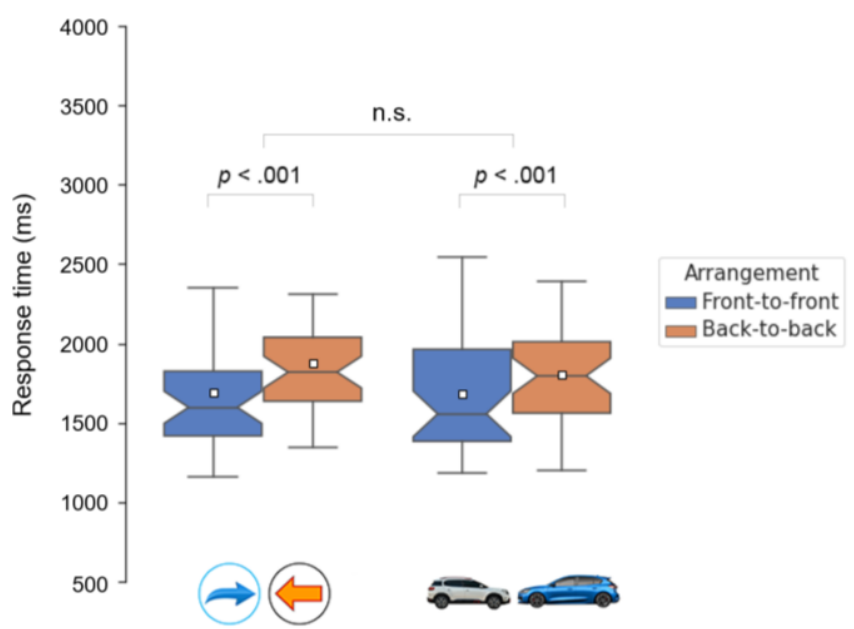

Figure S4. Results from the cars experiment. Boxes indicate inter-quartile range. Notches indicate confidence interval of the median. Whiskers indicate 1.5 * interquartile range. White squares denote the mean. 


\section{Chairs}

Results are shown in Figure S5. Those trials where participants responded incorrectly $(1.7 \%)$, or where they took longer than $5 \mathrm{~s}$ to respond $(1.0 \%)$, were excluded from the analysis. The search advantage for facing dyads was seen independently for arrows. Front-to-front targets $(M=1.73 \mathrm{~s}, S D=0.42 \mathrm{~s})$ were found significantly faster than back-to-back targets $(M=1.96$ $\mathrm{s}, S D=0.54 \mathrm{~s})\left[t(39)=5.71, p<.001, d_{z}=0.90, \mathrm{Cl}_{95 \%}=0.15 \mathrm{~s}, 0.32 \mathrm{~s}\right]$. ANOVA with Arrangement (front-to-front, back-to-back) and Stimulus (arrows, chairs) as within-subjects factors revealed a significant Arrangement $\times$ Stimulus interaction $[F(1,39)=5.55, p=.024$, $\left.\eta \mathrm{p}^{2}=.13\right]$. No correlation was seen between participants' search advantage for arrows and chairs $\left[r_{p}=.006, p=.971\right]$.

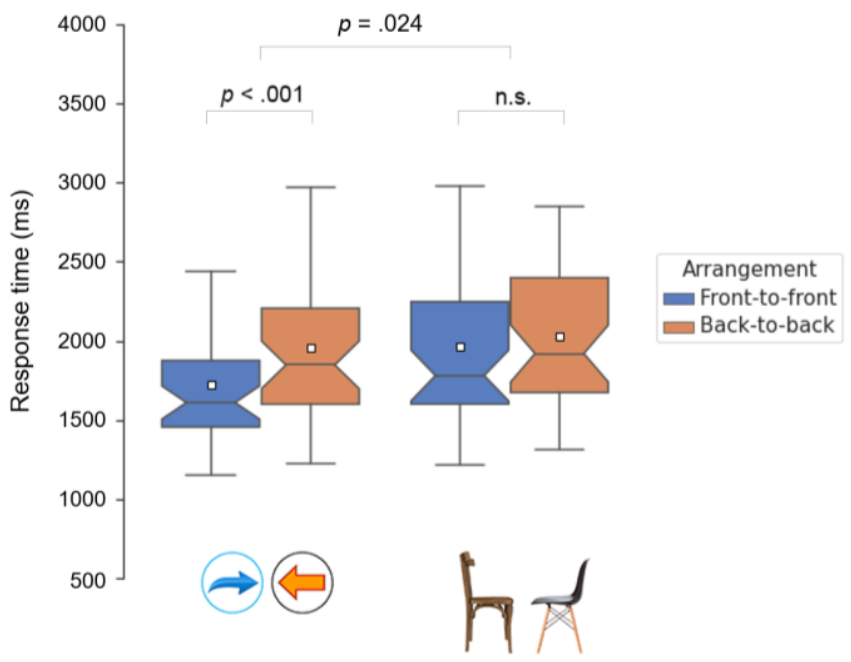

Figure S5. Results from the chairs experiment. Boxes indicate inter-quartile range. Notches indicate confidence interval of the median. Whiskers indicate 1.5 * interquartile range. White squares denote the mean.

\section{Desk fans}

Results are shown in Figure S6. Those trials where participants responded incorrectly (1.8\%), or where they took longer than $5 \mathrm{~s}$ to respond $(1.2 \%)$, were excluded from the analysis. The search advantage for facing dyads was seen independently for arrows. Front-to-front targets $(M=1.73 \mathrm{~s}, S D=0.34 \mathrm{~s})$ were found significantly faster than back-to-back targets $(M=1.93$ $\mathrm{s}, S D=0.41 \mathrm{~s})\left[t(39)=5.79, p<.001, d_{z}=0.92, \mathrm{Cl}_{95 \%}=0.13 \mathrm{~s}, 0.26 \mathrm{~s}\right]$. ANOVA with Arrangement (front-to-front, back-to-back) and Stimulus (arrows, desk fans) as within-subjects factors revealed no Arrangement $\times$ Stimulus interaction $\left[F(1,39)=1.53, p=.223, n p^{2}=.04\right]$. A significant correlation was seen between participants' search advantage for arrows and desk fans $\left[r_{p}=.460, p=.003\right]$.

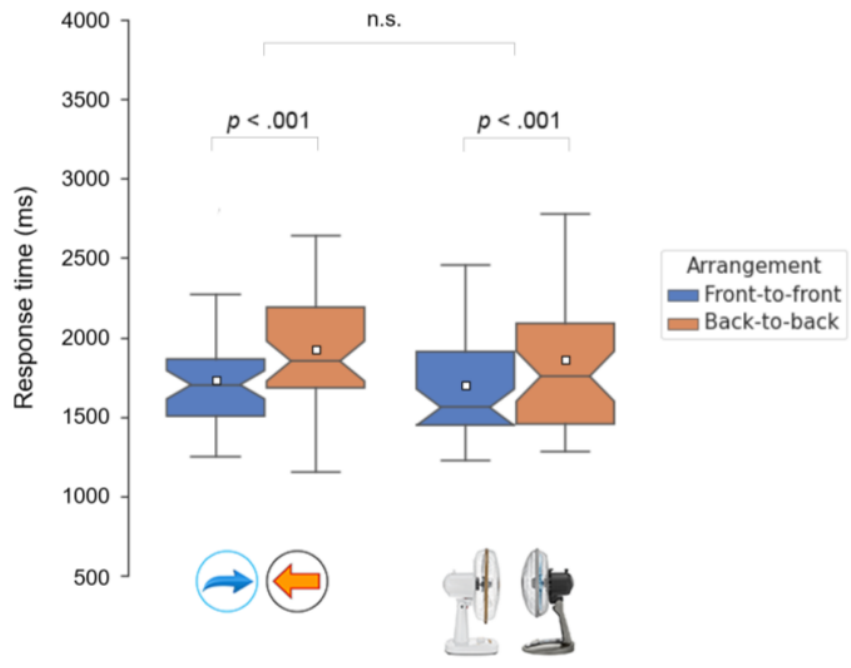

Figure S6. Results from the desk fans experiment. Boxes indicate inter-quartile range. Notches indicate confidence interval of the median. Whiskers indicate $1.5^{*}$ interquartile range. White squares denote the mean. 


\section{Guns}

Results are shown in Figure S7. Those trials where participants responded incorrectly $(1.7 \%)$, or where they took longer than $5 \mathrm{~s}$ to respond $(0.9 \%)$, were excluded from the analysis. The search advantage for facing dyads was seen independently for arrows. Front-to-front targets $(M=1.68 \mathrm{~s}, S D=0.39 \mathrm{~s})$ were found significantly faster than back-to-back targets $(M=1.82$ $\mathrm{s}, S D=0.39 \mathrm{~s})\left[t(39)=5.05, p<.001, d_{z}=0.80, \mathrm{Cl}_{95 \%}=0.08 \mathrm{~s}, 0.19 \mathrm{~s}\right]$. ANOVA with

Arrangement (front-to-front, back-to-back) and Stimulus (arrows, guns) as within-subjects factors revealed a significant Arrangement $\times$ Stimulus interaction $[F(1,39)=8.23, p=.007$, $\left.\eta \mathrm{p}^{2}=.17\right]$. No correlation was seen between participants' search advantage for arrows and guns $\left[r_{p}=.161, p=.321\right]$

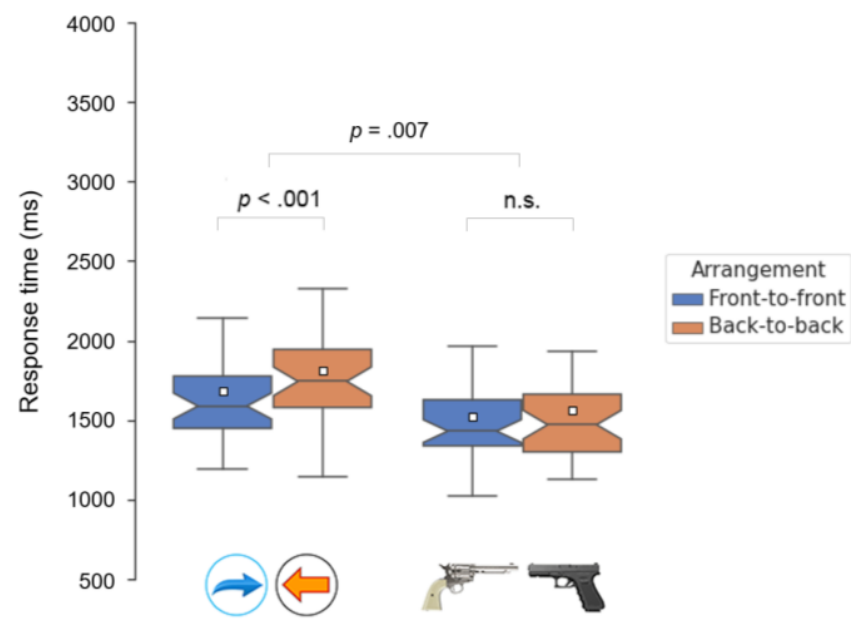

Figure S7. Results from the guns experiment. Boxes indicate inter-quartile range. Notches indicate confidence interval of the median. Whiskers indicate $1.5^{*}$ interquartile range. White squares denote the mean.

\section{Desk lamps}

Results are shown in Figure S8. Those trials where participants responded incorrectly $(1.7 \%)$, or where they took longer than $5 \mathrm{~s}$ to respond $(1.1 \%)$, were excluded from the analysis. The search advantage for facing dyads was seen independently for arrows. Front-to-front targets $(M=1.76 \mathrm{~s}, S D=0.43 \mathrm{~s})$ were found significantly faster than back-to-back targets $(M=1.97$ $\mathrm{s}, S D=0.41 \mathrm{~s})\left[t(39)=5.46, p<.001, d_{z}=0.86, \mathrm{Cl}_{95 \%}=0.13 \mathrm{~s}, 0.28 \mathrm{~s}\right]$. ANOVA with Arrangement (front-to-front, back-to-back) and Stimulus (arrows, desk lamps) as withinsubjects factors revealed no Arrangement $\times$ Stimulus interaction $\left[F(1,39)=0.27, p=.606, n p^{2}\right.$ $=.01]$. No correlation was seen between participants' search advantage for arrows and desk lamps $\left[r_{p}=.190, p=.240\right]$.

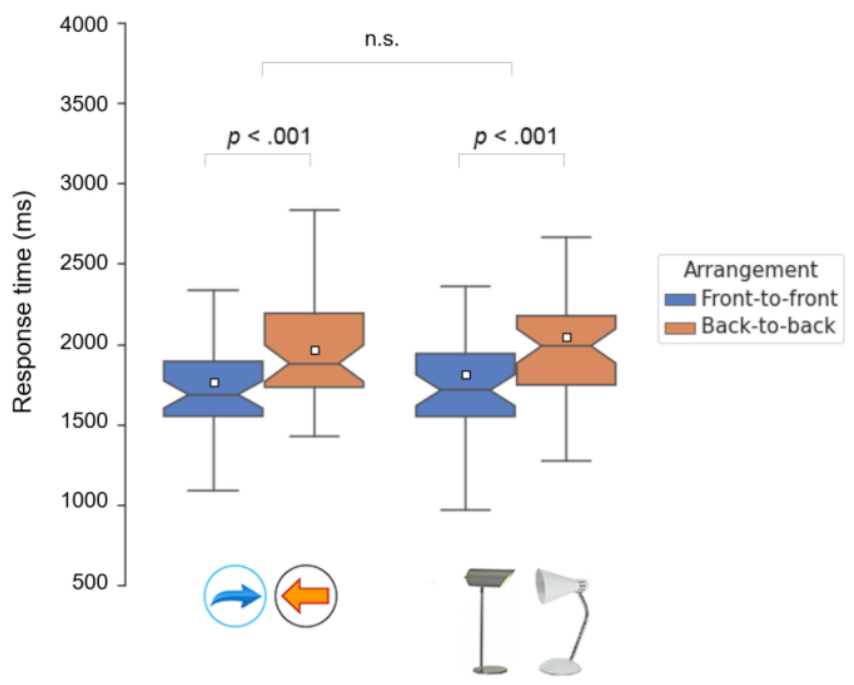

Figure S8. Results from the desk lamps experiment. Boxes indicate inter-quartile range. Notches indicate confidence interval of the median. Whiskers indicate 1.5 * interquartile range. White squares denote the mean. 


\section{Bicycles}

Results are shown in Figure S9. Those trials where participants responded incorrectly $(1.5 \%)$, or where they took longer than $5 \mathrm{~s}$ to respond $(0.8 \%)$, were excluded from the analysis. The search advantage for facing dyads was seen independently for arrows. Front-to-front targets $(M=1.41 \mathrm{~s}, S D=0.20 \mathrm{~s})$ were found significantly faster than back-to-back targets $(M=1.61$ $\mathrm{s}, S D=0.33 \mathrm{~s})\left[t(39)=4.59, p<.001, d_{z}=0.72, \mathrm{Cl}_{95 \%}=0.11 \mathrm{~s}, 0.29 \mathrm{~s}\right]$. ANOVA with Arrangement (front-to-front, back-to-back) and Stimulus (arrows, cameras) as within-subjects factors revealed a significant Arrangement $\times$ Stimulus interaction $\left[F(1,39)=5.98, p=.019, \eta_{p}^{2}\right.$ $=.13]$. A significant correlation was seen between participants' search advantage for arrows and bicycles $\left[r_{p}=.415, p=.008\right]$.

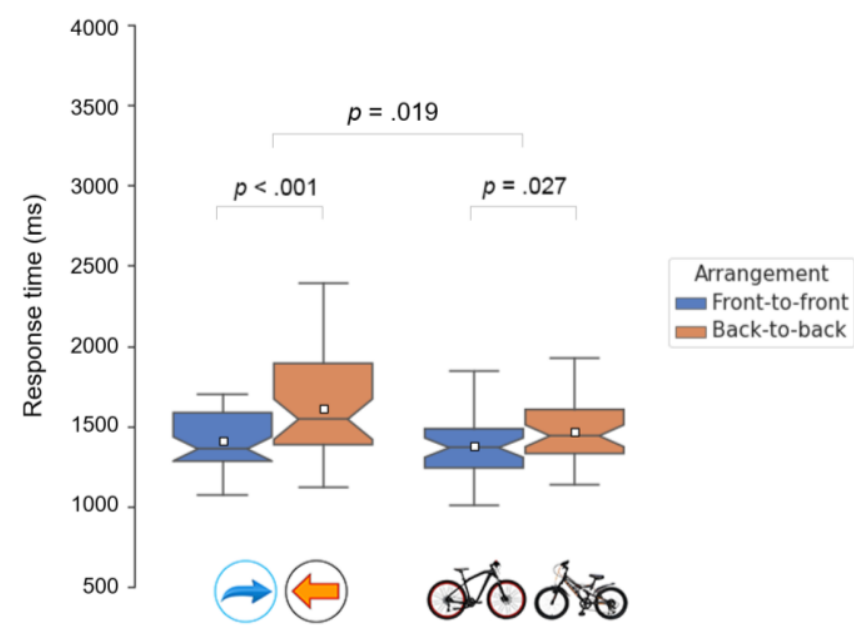

Figure S9. Results from the bicycles experiment. Boxes indicate inter-quartile range. Notches indicate confidence interval of the median. Whiskers indicate $1.5^{*}$ interquartile range. White squares denote the mean.

\section{Drills}

Results are shown in Figure S10. Those trials where participants responded incorrectly $(1.7 \%)$, or where they took longer than $5 \mathrm{~s}$ to respond $(1.0 \%)$, were excluded from the analysis. The search advantage for facing dyads was seen independently for arrows. Front-tofront targets $(M=1.47 \mathrm{~s}, S D=0.22 \mathrm{~s})$ were found significantly faster than back-to-back targets $(M=1.74 \mathrm{~s}, S D=0.31 \mathrm{~s})\left[t(39)=6.37, p<.001, d_{z}=1.01, \mathrm{Cl}_{95 \%}=0.19 \mathrm{~s}, 0.36 \mathrm{~s}\right]$. ANOVA with Arrangement (front-to-front, back-to-back) and Stimulus (arrows, cars) as withinsubjects factors revealed no Arrangement $\times$ Stimulus interaction $\left[F(1,39)=0.76, p=.390, n_{\mathrm{p}}^{2}\right.$ $=.02]$. A significant correlation was seen between participants' search advantage for arrows and drills $\left[r_{p}=.424, p=.006\right]$.

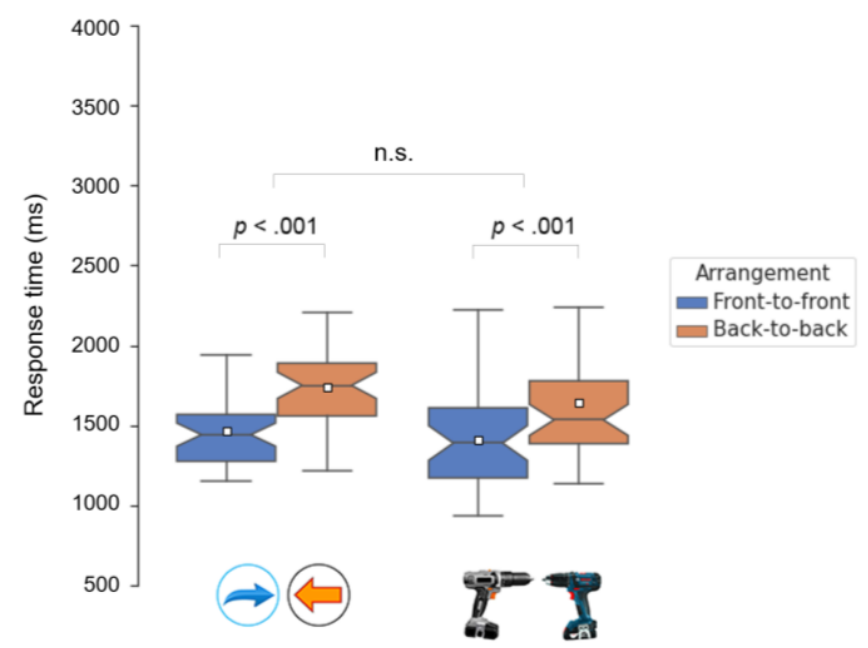

Figure S10. Results from the power drills experiment. Boxes indicate inter-quartile range. Notches indicate confidence interval of the median. Whiskers indicate $1.5^{*}$ interquartile range. White squares denote the mean. 


\section{Shoes}

Results are shown in Figure S11. Those trials where participants responded incorrectly $(1.8 \%)$, or where they took longer than $5 \mathrm{~s}$ to respond $(1.2 \%)$, were excluded from the analysis. The search advantage for facing dyads was seen independently for arrows. Front-tofront targets $(M=1.46 \mathrm{~s}, S D=0.34 \mathrm{~s})$ were found significantly faster than back-to-back targets $(M=1.60 \mathrm{~s}, S D=0.38 \mathrm{~s})\left[t(39)=3.47, p=.001, d_{z}=0.55, \mathrm{Cl}_{95 \%}=0.06 \mathrm{~s}, 0.21 \mathrm{~s}\right]$. ANOVA with Arrangement (front-to-front, back-to-back) and Stimulus (arrows, chairs) as within-subjects factors revealed no Arrangement $\times$ Stimulus interaction $[F(1,39)=3.01, p=$ $\left..091, \mathrm{np}^{2}=.07\right]$. No correlation was seen between participants' search advantage for arrows and shoes $\left[r_{p}=.109, p=.503\right]$.

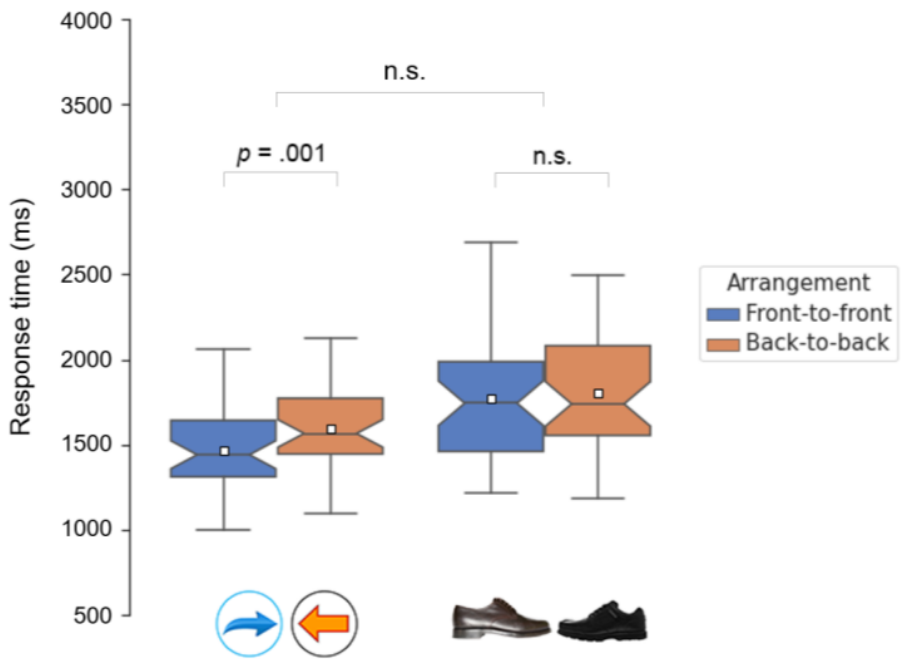

Figure S11. Results from the shoes experiment. Boxes indicate inter-quartile range. Notches indicate confidence interval of the median. Whiskers indicate $1.5^{*}$ interquartile range. White squares denote the mean. 